\title{
TRAJECTORY OF CONTAMINATED PARTICLE IN INTENSIVE CARE UNIT OF HOSPITALS USING NUMERICAL MODELING
}

\author{
Tikendra Nath Verma $A^{1}$, Shobha Lata Sinha $A^{2}$ \\ 1,2National Institute of Technology Raipur,492010, India \\ Email: 1verma_tikendra@yahoo.co.in
}

\begin{abstract}
Primary objective of air-conditioning is to create an indoor air quality and thermal condition of comfort suitable for persons / patients, with minimum energy cost. In air-conditioning system, ventilation airflow rate is the amount of fresh outdoor air introduced into the room to dilute $\mathrm{CO}_{2}$, contaminants and odours etc. Numerical model solves mass, momentum and energy equations. The contaminated particle (infection) which is simulated with a Lagrangian particle tracking model and the same has been carried out by simulation. This is usually a small part of the supply airflow rate which is introduced and distributed into the room at proper flow rate, velocity, temperature and relative humidity so as to remove the thermal loads and obtain conditions of thermal comfort. This is filtered to remove contaminants, mixed with ventilation air and conditioned by cooling / heating and humidifying / dehumidifying before introduction into the room. The study concerns about the health risk of the airborne diseases (bacteria, fungus, viruses etc.) from the patient to the other people in the ICU of hospital. By observing the movement of contaminated particle, it is advisable to keep the nurse- station and health care staff near the inlet to keep them healthy.
\end{abstract}

Key words: CFD, Contaminated particle, $k-\varepsilon$ model, Turbulent flow

\section{I.INTRODUCTION}

Airborne precautions were advised after the severe acute respiratory syndrome (SARS) epidemic for patients infected with open pulmonary tuberculosis, measles, smallpox and chickenpox. In present scenario, there is no clear definition or a precise list of high-risk health-care procedures during which some pathogens can be spread through droplet nuclei over short distances. Each person consciously or unconsciously determines whether he or she is comfortable at a particular time and location. The design must provide a ventilation system that minimizes exposure hazards for health care providers and provides a comfortable working environment. HVAC (Heating Ventilation \& Air Conditioning) system must also provide ventilation that minimizes the hazard exposure of visitors.

\section{LITERATURE REVIEW}

According to Wallace (1996) and Wang et.al. (1998), people spend more than $80 \%$ of their life time in inside areas. Indoor air quality has a significant role in human comfort, health and safety (Sandberg (1983)). It is essential to make clear, the principle of non-uniform distribution of indoor contaminant and know how to utilize the non-uniform principle to create various indoor parameters so that better design and control on the HVAC system can be obtained (Cai (2008)). Numerical simulation is another way to predict the contaminant distribution which is based on the development of computational fluid dynamics (CFD). Xiaojun et al. (2012) have presented that there is no direct relationship to quantify the transient influence of different boundary conditions including contaminant in supply air, contaminant source and initial condition on indoor contaminant distribution. The proposed expression can explicitly and quantitatively reflect the effect of supply air, contaminant source and initial condition on the contaminant distribution indoors. An experimental study is executed to validate the reliability of the analytical expression. It is depicted that the present results compare well with experimental measurement. It was revealed that the critical contamination source was the stocker and the contaminants were transferred by the airflow pattern.

Woods et al. (1986) have presented a study to identify and demonstrate control strategies that could reduce energy requirements while not producing 
harmful effects on the environmental quality within the operating room. It was done through biophysical models, extensive literature search, development of mathematical expression and, analysis of result obtained in the couple of existing operating rooms with different system performance characteristics. Lewis et al. (1993) have studied the influence of room air distribution on the infection rate in an operating room and concluded that an optimal air distribution plays an important role in maintaining the proper environmental condition within a surgical room. Boswell and Fox (2006) have showed reduction in surface contamination when portable air cleaning devices were deployed, clearly indicating that airborne transport plays a role in the dispersion of Methicillin Resistant Staphylococcus aureus (MRSA) in the environment. The release of particles contaminated with MRSA into the air may occur from the skin which is shed during routine activities such as walking, bed making, undressing and washing. Balaras et al. (2002) have presented an overview of general design for acceptable indoor conditions related to HVAC systems in hospital operating rooms. Audits of 20 operating rooms in 10 hospitals were recorded covering a wide range of information on the detail about type condition of HVAC,auxiliary systems, construction and ventilating system.
Computational fluid dynamics (CFD) models are used to predict the air velocity, turbulence level \& air temperature. In order to predict airflow in an ICU, the flow equation must account for turbulence and buoyancy. Conservation equations for mass, momentum \& energy can be formulated for every cell. Three dimensional General Transport equations for turbulent flow are given below:

$$
\begin{aligned}
& \frac{\partial(\rho \phi)}{\partial t}=\frac{\partial \phi}{\partial x}\left(\Gamma_{\phi} \frac{\partial \phi}{\partial x}-\rho u \phi\right) \\
& +\frac{\partial \phi}{\partial y}\left(\Gamma_{\phi} \frac{\partial \phi}{\partial y}-\rho v \phi\right) \\
& +\frac{\partial \phi}{\partial z}\left(\Gamma_{\phi} \frac{\partial \phi}{\partial z}-\rho w \phi\right)+S_{\phi}
\end{aligned}
$$

Table 1 shows the details of variables $\phi, \Gamma_{\phi}$ and $S_{\phi}$ for various conservation equations. The inlet velocity $U_{0}$ and inlet opening $W_{1}$ are taken as characteristic velocity and length respectively. The skin temperature of human body $\left(T_{h}\right)$ is $37^{\circ} \mathrm{C}$. The difference between inlet air temperature and maximum wall temperature $(\Delta T)$ has been used for non-dimensionlization of temperature. Table 2 shows the different temperature on the walls.

\section{GOVERNING EQUATION}

Table 1. Notations for Governing Equations in Cartesian Co-ordinates for Turbulent Flow

\begin{tabular}{|c|c|c|c|}
\hline Equation & $\phi$ & $\Gamma_{\phi}$ & $S_{\phi}$ \\
\hline Continuity & 1 & 0 & 0 \\
\hline u-momentum & $\mathrm{u}$ & $\frac{1}{R e}+\frac{\mu_{t}}{R e}$ & $-\frac{\partial p}{\partial x} \frac{\partial p}{\partial x}+\frac{\partial}{\partial x}\left(\Gamma_{\phi} \frac{\partial u}{\partial x}\right)+\frac{\partial}{\partial y}\left(\Gamma_{\phi} \frac{\partial v}{\partial x}\right)+\frac{\partial}{\partial z}\left(\Gamma_{\phi} \frac{\partial w}{\partial x}\right)$ \\
\hline $\mathrm{V}$-momentum & $\mathrm{V}$ & $\frac{1}{R e}+\frac{\mu t}{R e}$ & $-\frac{\partial p}{\partial y}+\frac{\partial}{\partial x}\left(\Gamma_{\phi} \frac{\partial u}{\partial y}\right)+\frac{\partial}{\partial y}\left(\Gamma_{\phi} \frac{\partial v}{\partial y}\right)+\frac{\partial}{\partial z}\left(\Gamma_{\phi} \frac{\partial w}{\partial y}\right)+\left(\frac{G r}{R e}\right) T$ \\
\hline W-momentum & $\mathrm{W}$ & $\frac{1}{R e}+\frac{\mu_{t}}{R e}$ & $-\frac{\partial p}{\partial z}+\frac{\partial}{\partial x}\left(\Gamma_{\phi} \frac{\partial u}{\partial z}\right)+\frac{\partial}{\partial y}\left(\Gamma_{\phi} \frac{\partial v}{\partial z}\right)+\frac{\partial}{\partial z}\left(\Gamma_{\phi} \frac{\partial w}{\partial z}\right)$ \\
\hline Energy & $\mathrm{T}$ & $\frac{1}{R e P_{r}}+$ & 0 \\
\hline $\begin{array}{c}\text { Turbulence } \\
\text { Kinetic energy }\end{array}$ & $\mathrm{K}$ & $\frac{1}{R e}+\frac{\mu_{t}}{R_{t} P_{r t}}$ & $\frac{\mu_{t}}{\sigma_{k} R e}$ \\
\hline $\begin{array}{c}\text { Heat } \\
\text { dissipation } \\
\text { rate }\end{array}$ & $\epsilon$ & $\frac{1}{R e}+\frac{\mu_{t}}{\sigma_{\epsilon} R e}$ & $\frac{\epsilon}{k}\left(C_{1} f_{1} G_{k}-C_{2} f_{2} \rho \epsilon+C_{3} G_{b}\right)$ \\
\hline
\end{tabular}




\section{ASSUMPTION USED IN MODELING}

The following assumptions are used for numerical modeling of the airflow:

- The bed, doctor, patient \& enclosure are of the shape of rectangular boxes.

- The room is considered to be well insulated including the walls, floor and ceiling.

- Patient is considered to be lying on the bed in the east-west direction.

- When one patient is considered to be infected, other patients are assumed to produce no contamination;

- The movement of only one particle has been considered during study for clarity in the figures;

- Contaminants have been considered mass less and alcoholic (i.e. ethyl alcohol liquid) in nature.

Table 2 Temperature on Different Walls (in 'C)

\begin{tabular}{|c|c|c|c|c|}
\hline East & West & North & South & Ceiling \\
\hline 31 & 25 & 17 & 28 & 48 \\
\hline
\end{tabular}

\section{RESULTS \& DISCUSSION}

In simulation work, three different positions of inlet and outlet for different values of Reynolds number have been considered with and without enclosures. In general total 12 cases have been considered for numerical investigation by altering the position of inlet. The inlet and outlet area is kept constant throughout the simulation as $0.6 \mathrm{~m} \times 0.4 \mathrm{~m}$. The air is supplied at three different velocities which have been categorized in three different cases. Patient is considered to be lying on the bed in the north-south direction as shown in figure 1.

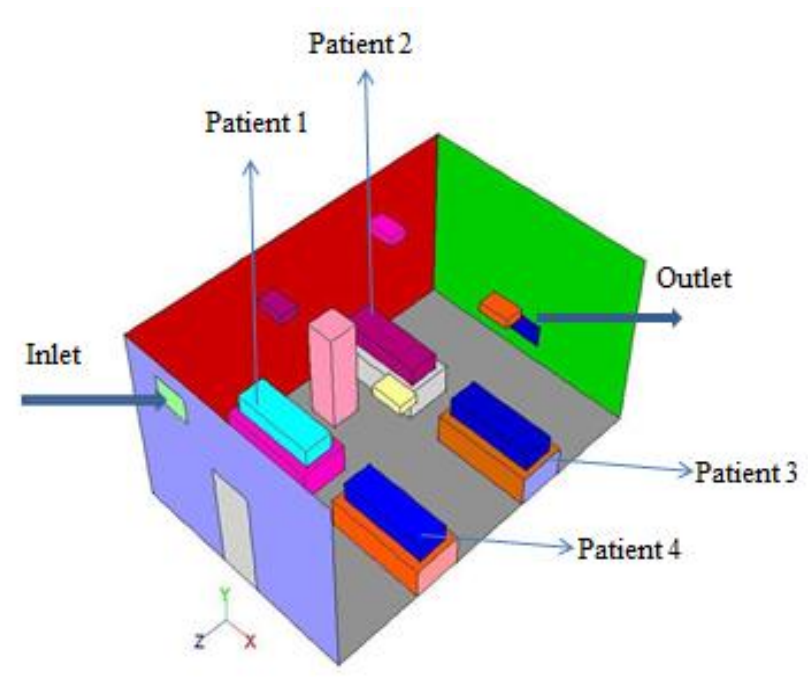

(a) Without Enclosure (WOE)

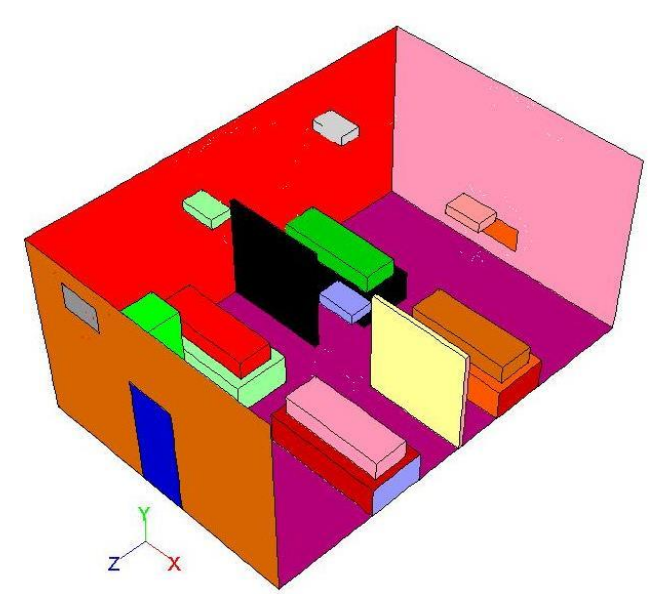

(b) With Enclosure (WE)

Fig.1 Room Layout of Multi-Patient Intensive Care Units (Case 1-2)

\section{A. Case 1: Inlet $600 \mathrm{~mm}$ in front of west wall (WOE)}

Figure 2 (a-d) show the movement of massless contaminated particle from the mouth of patient for inlet air velocity of $1.0 \mathrm{~m} / \mathrm{s}$. Figure 2 (a) shows that the contaminated particle starts from the mouth of patient 1 and it simply leaves through the outlet without affecting the doctor/ nurse / other patients. The total time taken by the mass less contaminated particle is approximately 9.18 seconds to leave the room of ICU. Figure 2 (b) shows the contaminated particle starts from the mouth of patient 2 and moves through tortuous path. The path of contaminated particle is relatively above the 
occupied zone and leaves through the outlet without affecting the doctor or other patients. The total time taken by the mass less contaminated particle is approximately 4.25 seconds to leave the room. Figure 2 (c) shows that the contaminated particle starts from the mouth of patient 3 and then the contaminated particle moves in the direction of south wall and subsequently it exits through the outlet. The overall time taken by the mass less contaminated particle is approximately 4.1 minutes to leave the room in this case. Figure 2 (d) shows the contaminated particle starts from the mouth of patient 4, then it moves towards south wall and leaves through the outlet without affecting the doctor or other patients. The total time taken by the mass less contaminated particle is approximately 1.95 minutes to leave the room.

\section{B. Case 2: Inlet $600 \mathrm{~mm}$ in front of west wall (WE)}

Figures $3(a-d)$ show the movement of mass less contaminated particle from the mouth of patients when enclosure has been provided between patients. Figure 3 (a) shows that the contaminated particle starts from the mouth of patient 1 and then it simply leaves through the outlet without affecting the doctor/patients. The total time taken by the mass less contaminated particle is approximately 7.63 minutes to leave the room. Figure 3 (b) shows the contaminated particle starts from the mouth of patient 2 and moves through tortuous path. The total time taken by the mass less contaminated particle is approximately 4.16 minutes to leave the room. The contaminated particle does not affect any other patients as well as doctor. In this case particle takes less time in comparison to the case of patient 1 (figure 3 a). Figure 3 (c) shows that the contaminated particle starts from the mouth of patient 3 and it moves in the direction of south wall and after that, it simply leaves through the outlet. The total time taken by the contaminant is approximately 5.17 seconds to leave the room of ICU. Figure 3 (d) shows that the contaminated particle starts from the mouth of patient 4 and then it moves in the direction of south wall after that it leaves through the outlet without affecting the doctor or patients. The total time taken by the mass less contaminated particle is approximately 6.25 minutes to leave the room of ICU.

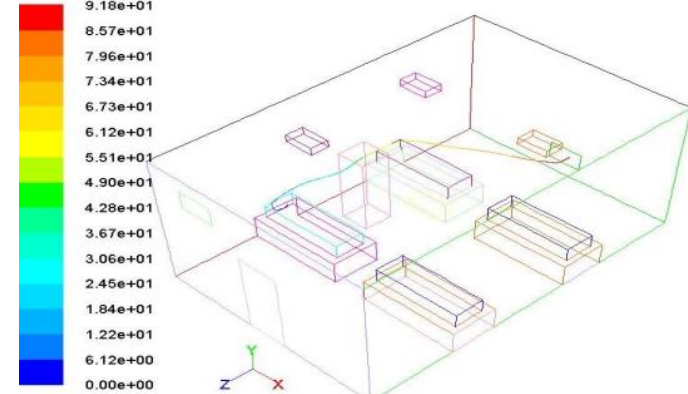

(a) Movement of Contaminant Particle (Patient 1)

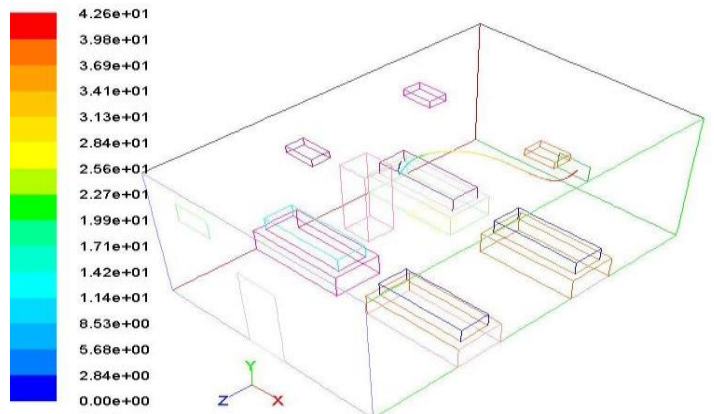

(b) Movement of Contaminant Particle (Patient 2)

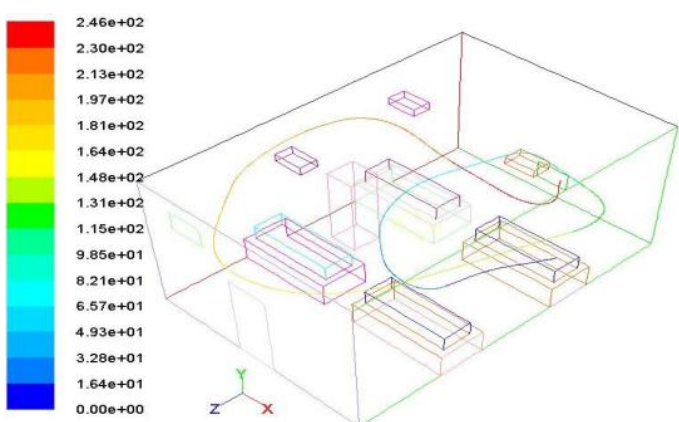

(c) Movement of Contaminant Particle (Patient 3)

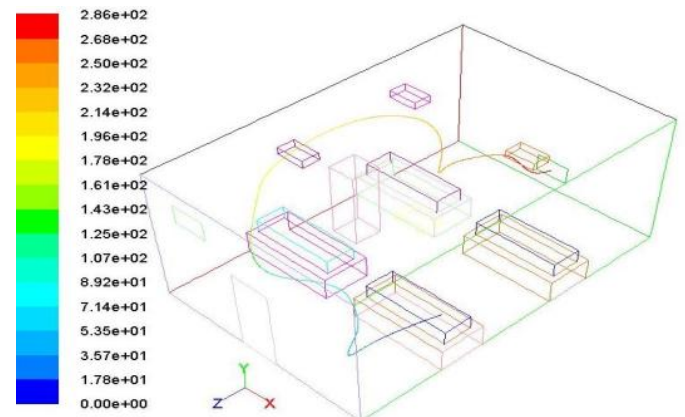

(d).Movement of Contaminant Particle (Patient 4)

Fig.2 Results of Numerical Simulation without Enclosure $(\mathrm{WOE})($ Velocity $=1.0 \mathrm{~m} / \mathrm{s})$ 


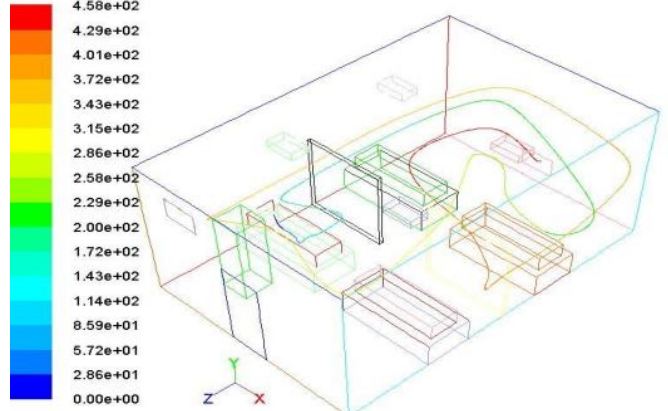

(a). Movement of Contaminant Particle (Patient.1)

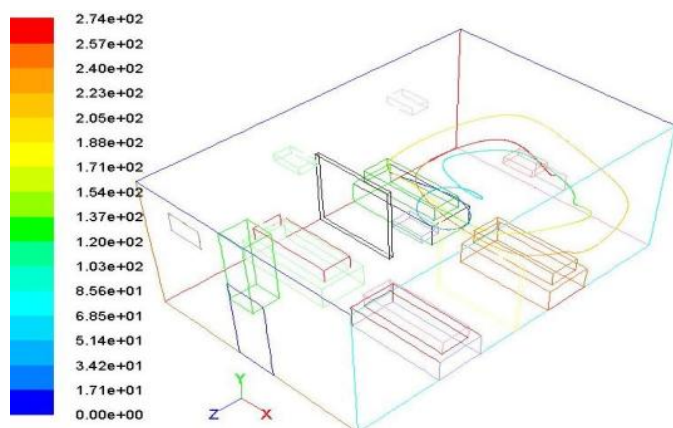

(b).Movement of Contaminant Particle (Patient 2)

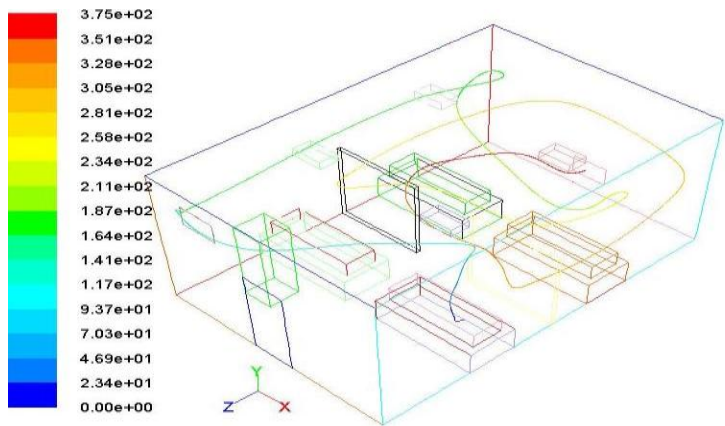

(c) Movement of Contaminant Particle (Patient 3)

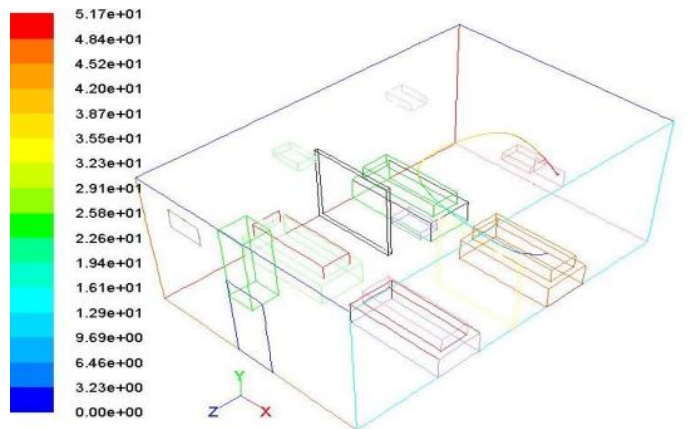

(d) Movement of Contaminant Particle (Patient 4)

Fig.3 Results of Numerical Simulation with Enclosure $($ Velocity $=1.0 \mathrm{~m} / \mathrm{s})$

\section{CONCLUSION}

The studies have been carried out for different inlet velocities of $0.5 \mathrm{~m} / \mathrm{sec}$ and $1.0 \mathrm{~m} / \mathrm{sec}$ in ICU with and without enclosure using $k-\varepsilon$ model. It is observed that the effect of cooling is more prominent when the ICU is not provided enclosures between the patients. The flow of contaminated particle, discharged from the mouth of patient is not safe when enclosure is not provided. In order to maintain the healthy environment, the infected patient must be provided enclosure and siting must be done according to the airflow pattern. By observing the movement of contaminated particle, it is advisable to keep the nurse-station and health care staff near the inlet to keep them healthy.

\section{REFERENCES}

[1] Balaras C A, Dascalaki E, Argiriou A A, Gaglia A, 2002 , HVAC systems and indoor conditions in Hellenic hospital operating rooms, ASHRAE Transactions, 108 (2), 23-38.

[2] Boswell T C, Fox P C, 2006, Reduction in MRSA environmental contamination with a portable HEPA-filtration unit, Journal of Hospital Infection, 63(1), 47-54.

[3] Cai, H., Li, X., 2008, Balancing indoor environment quality and energy use with a human-oriented evaluation method of indoor air distribution. In Proceedings of first international conference on building energy and environment (COBEE), Dalian, China, 2474-81.

[4] Lewis J R, 1993, Operating room air distribution effectiveness, ASHRAE Transactions, 99 (2), 1191-1199.

[5] Sandberg, M., Sjoberg, M., 1983, The use of moments for assessing air quality in ventilated rooms. Building Environment, 18(4), 181-197.

[6] Wallace, L., 1996, Indoor particles: a review. Journal of Air Waste Manage Association, 46, 98-126.

[7] Wang, J., Cao, S., Li, Z., Zhang, Y., Li, S., 1998, Human exposure to carbon monoxide and inhalable particulate in Beijing, China. Biomed Environ Science, 1(1), 5-12.

[8] Woods J E, Brayman D T, Rasmussen R W, Reynolds P E, Montag G M, 1986, Ventilation requirements in hospital operating rooms, Part 1: Control of airborne particles, ASHRAE Transactions, 92 (2), 396-426.

[9] Xiaojun, M., Xiaoliang, S., Xianting, L., Yiwei, L., 2012, An analytical expression for transient distribution of passive contaminant under steady flow field, Building and Environment, 52, 98-106. 